\title{
Un tempo propio
}

David BARREIRO

Este texto foi lido na homenaxe a Herminio Barreiro, celebrada o 17 de febreiro de 2011 no paraninfo da facultade de Xeografía e Historia da Universidade de Santiago de Compostela. Quero reiterar, polo tanto, o meu agradecemento á Fundación 10 de marzo, especialmente a Ricardo Gurriarán, así como ás demais entidades colaboradoras, pola oportunidade que brindaron á familia de compartir esta homenaxe cos amigos, colegas e compañeiros de Herminio.

Tamén quero dedicar este texto á muller de Herminio, Mercedes Martínez, falecida recentemente. Unha muller sen a que as andanzas de Herminio terían sido moito máis difíciles. Unha muller, como di Silvio, desas que están "siempre a la sombra y llenando un espacio vital”, e ás que ninguén lle fará nunca unha homenaxe pública.

Como algúns achegados xa saben, desde a publicación de Recordar doe, el andaba dándolle voltas á idea de escribir unha segunda parte, centrada nos seus anos de maxisterio, xa que a primeira relataba os anos de aprendizaxe. Cando nos propuxeron participar neste acto, pensamos que sería unha boa idea relatar as notas que puidese ter escrito ata o momento, ou unha parte delas. Por desgraza, non atopamos ningún material deste tipo no seu ordenador; tampouco ningún manuscrito. $\mathrm{O}$ que si atopamos foi 0 índice deste proxecto de libro, organizado en cinco partes. Pensamos, entón, que podiamos abrir o noso álbum de fotos, xa que estamos aquí en representación da familia, e compartir con vós algunhas evocacións suxeridas polas escenas e retratos que alí atopamos, seguindo, iso si, a orde temporal na que el pensaba estruturar este segundo volume de memorias, que ía titular Un tempo propio.

\section{Francia}

A primeira parte do libro ía levar o título de "Doce Francia (1965-1967)". Francia, para Herminio, era máis que un país: era a suma dun concepto e dunha vivencia. Alí pasou os dous anos seguintes á súa licenciatura. Do primeiro ano conservamos unha fotografía en cor, tomada durante un dos seus paseos, na ribeira do Lago de Menet, ao sur de Montluçon (Figura 1). Na foto aparecen uns recén casados Herminio e Merche, que suxeita na man un ramo de flores silvestres, escoltados por Janinne, a muller de Gilbert. Os Dugne eran os mellores amigos de Herminio e Merche en Francia. Con eles pasaron o Nadal de 1966, en París, nunha primeira viaxe a unha cidade que os dous conservarían sempre na memoria, como primeira fuxida da grisácea opresión da España franquista. É París, ás veces os tópicos son certos, como Cidade da Luz, berce desa llustración á que Herminio 
endexamais renunciou. Nunha imaxe de 1983 achamos a Herminio a carón de Antón Costa e Narciso de Gabriel, fronte ao monumento a Jules Ferry, testemuña dunha nova viaxe á capital francesa que reportaría á familia numerosas anécdotas (Ver fotobiografía 1983).

Lembranzas de Francia xurdían con frecuencia nas conversas familiares. Vivencias políticas, xa que en Francia foi onde Herminio coñeceu a algúns destacados membros do Partido, alí exiliados, consolidando así o seu compromiso ideolóxico, iniciado nos seus anos de estudante. E vivencias persoais, profundas e arraigadas, primaverais como a imaxe da primeira fotografía. Na casa nunca faltaron os discos de Jacques Brel, de Edith Piaff, de George Moustaki, de Leo Ferré... Discos que desprendían, e, para nós, seguen a desprender, un aroma a saudade, a nostalxia daqueles anos vividos na doce Francia, que nin sequera chegaron a ser dous, pero que ficaron gravados no imaxinario familiar para sempre, e pasaron a formar parte indeleble do acervo intelectual e sentimental de Herminio: "Recuerdo con cariño las tertulias de atardecer, en las que paseaba con los alumnos por las calles de Montluçon y Avignon. [...] Estos vínculos se mantuvieron ya para toda la vida y significaron mucho para mí, pues cuando me dediqué a estudiar la historia de la educación en Europa entro en una línea erudita de investigación, sobre la cultura que yo había experimentado de una manera tan viva en los años 60". (La educación como diálogo; entrevista de Gena Borrajo a Herminio Barreiro, Cuadernos de Pedagogía, 2005).

\section{Madrid, Cuba}

O seu regreso de Francia, en 1967, coincide co nacemento da súa filla, a primoxénita. De feito, Merche retorna uns meses antes que el. Entre 1967 e 1976 a familia vivirá en Madrid. Así é como pensaba titular esta segunda parte do libro: "Vivir en Madrid (19671976)": vivir en familia, se entende, unha nova vida, pois en Madrid xa experimentara moitas cousas antes. Durante eses anos traballou como profesor de primaria e secundaria en Carabanchel. Como el mesmo dixo: "En Madrid trabajé en un contexto complicado. Los alumnos presentaban problemas derivados de entornos sociales y familiares difíciles. Con frecuencia tenía que imponerme con rotundidad, lo que me generaba grandes dudas y contradicciones. Pero, al final, la experiencia me proporcionó una enseñanza muy importante: que la relación con los alumnos debía producirse en un entorno de afectividad. Aún hoy conservo gratísimos recuerdos de entonces y mantengo relaciones de amistad con antiguos alumnos y compañeros" (ob. cit.). Aínda hai pouco tempo puidemos recoller algunhas testemuñas, manifestadas a través do Facebook, de ex-alumnos que se lembran del. Foi emocionante comprobar a persistencia dese recordo. Tamén el acostumaba lembrar divertido e con cariño a eses alumnos seus de Carabanchel.

Cara 1970, a familia trasladouse a Aluche, moito máis preto do traballo, e da súa nai política, que vivía alí, soa. Vemos, nunha foto que debe ser algo anterior, a Herminio, sostendo nos seus brazos á súa filla (Figura 2). Ao fondo, unha parede de ladrillo. A filla mira á cámara sorprendida, pero o pai míraa a ela, medio de esguello, pero orgulloso. Aínda que parece feliz coa súa única filla, a familia creceu en 1971, co nacemento do segundo fillo. Para entón, tamén vivía en Madrid o seu irmán pequeno, coa súa muller, profesores igual que el. E o seu cuñado, que segue a vivir alí, tamén coa súa muller. A súa irmá, a 
mediana, andaba por terras de Extremadura, fogueándose cos rapaces de Fregenal de la Sierra. Tamén como profesora.

Pero ese mesmo ano de 1971 acontece algo decisivo: tras gañar un concurso, en agosto dese ano viaxou a Cuba. A Revolución Cubana, igual que a Francesa, sempre foi unha guía ideolóxica e, sobre todo, ética. Na nosa casa podías atopar o espírito de Cuba, encarnado en obxectos que el mesmo trouxera de alí (as figuriñas de artesanía, un sombreiro de palla, unha toalla de praia mínima -que seguiu utilizando durante décadas-, os discos de Carlos Puebla e Joseíto Fernández...) e nas cousas que lle enviaban de alí, ano tras ano: os carteis, os calendarios coas efixies dos libertadores ou as revistas. Tamén temos algunhas fotos daquela viaxe, pero a máis curiosa é unha na que se ve unha persoa, cortada, en primeiro plano, e aló, ao fondo, unha canoa con dúas persoas a bordo (Figura 3). Parecen unha muller e un home. $O$ río está tranquilo e ao fondo adivínase unha vexetación tropical. Polo reverso da foto hai unha nota: "Guamá. Agosto de 1971. Nota: Esta te la mando porque estás un poco lejos. Pronto las tendrás todas". Quizás isto dea unha idea, sobre todo aos que non chegamos a coñecer a ditadura, de ata que extremo podía chegar, naquela época, o temor a ser identificado coa subversión. Aínda así, Herminio nunca dubidou, e menos despois de visitar aquel país, de con quen había que estar.

O ano seguinte á morte do ditador, cando a súa filla xa vai á escola, Carlos Baliñas coméntalle a Herminio a oportunidade de presentarse a unha praza de profesor non numerario na facultade de Ciencias da Educación de Santiago de Compostela. É 1976, o ano do retorno á patria, logo de dezaoito anos de vida fóra de Galicia.

\section{Santiago}

As tres últimas partes deste proxecto de libro ían estar dedicadas á súa vida en Santiago, como profesor universitario. A primeira destas tres partes ía levar o título de "As camelias de Fonseca (1976-1979)". O propio título xa di todo o que para el supuña traballar nun sitio tan emblemático e fermoso. Co engadido da súa afección polas flores, e, en concreto, polas camelias. Quixo o destino que 016 de xuño de 2010 acudise alí para recibir a Insignia Fonseca xunto a outros colegas, en agradecemento aos seus anos de servizo á institución. Esa insignia forma parte, agora, do tesouro familiar.

Aqueles anos de finais dos '70 foron anos nos que a familia tivo que adaptarse aos cambios: nada problemáticos para os pequenos, un pouco máis difíciles para a súa muller, acostumada ao clima castelán. Por aqueles anos tamén retornaron a Galicia os seus irmáns, destinados en Vigo, co que, despois da diáspora, a familia estaba reunida outra vez aquí, en Galicia. E ampliada.

As viaxes a Sisán, onde residían, entón recén xubilados, os seus pais, pasaron dunha frecuencia semestral (no verán e no Nadal) a unha frecuencia semanal. Un cambio co que Herminio, supoñemos, estaba feliz. Por fin profesor dunha materia que adoraba e por fin en Galicia, en Compostela. Temos unha foto, en branco e negro, na que aparece el cos seus dous fillos, tamén en Sisán. Leva unha chaqueta escura, gafas de pasta e un pitillo na man 
(Figura 4). Unha estampa moi típica de el, naqueles anos. Como a que levaba cada día á facultade, e de aí ao Dakar, a cafetería á que sempre se acercaba nos descansos.

Pero o Dakar deixou de ser frecuentado, polo menos diariamente, cando trasladaron a facultade a Xoán XXIII, a carón da Escola de Maxisterio e do Colexio Nacional de Prácticas. Alí, "Preto do Camiño Francés", transcorreu o período entre os anos 1979 e 1986. A cuarta parte do libro. Anos intensos para toda a familia: os fillos que comezan o instituto, a nai que se ocupa deles con paciencia, e Herminio que le a tese, no 1982. Lembro que, durante os anos anteriores, o seu despacho estaba ateigado de cadernos Enri de cor rosa, os mesmos que utilizabamos no colexio. $E$ despois os cadernos transformáronse en folios e máis folios mecanografados na súa fiel Olivetti verde, para, finalmente, chegar un día Herminio á casa con varios volumes encadernados nun fermoso coiro de cor vermella, co título gravado na portada. A tese estaba acabada. Nós abríamos o libro con asombro, e cun secreto orgullo de fillos.

Herminio non facía unha distinción nítida entre o seu traballo e a súa vida: sempre aprendía (e aprehendía) cousas que lle axudaban no traballo, a formar ideas, a explicar conceptos. Por iso as viaxes con el -naquel 127 branco- eran fermosas: porque non se limitaba a pasar polos sitios e contemplar as paisaxes, senón que sempre atopaba a forma de integrar todas esas vivencias nun mesmo discurso, un discurso de respecto á natureza e de disfrute da mesma, de admiración polas obras humanas: as cidades, os monumentos, a gastronomía... Temos tantas fotos que poderían amosar isto..., pero quizás as que mellor o reflicten son as que nos facíamos cando parábamos a comer de campo (Figura 5) ou no entorno de Covarrubias (Figura 6). As dehesas de aciñeiras, as montañas, o mar, as paisaxes en xeral, sempre lle evocaban versos de poetas: Machado, Uxío, Lorca... Sempre atopaba conexións entre o mundo da literatura e o mundo vivido, e gustáballe viaxar ás paisaxes imaxinarias que atopaba nos libros.

No ano 1986, por fin, a familia trasladouse moi preto de onde vivira ata entón, pero a unha casa propia, a casa na que acabou de criar aos seus fillos e onde pasou estes últimos vinte e catro anos. A casa está na zona sur de Santiago, igual que a nova facultade, na que desenvolveu a maior parte da súa carreira docente na universidade. Quizais por isto pensaba titular a última parte do libro "Son do Sur (1986-2006)", para significarse como galego do sur de Galicia, ou como profesor universitario no Campus Sur, ou para aludir ao son que procede do mediodía, ou para evocar esa música que tanto amaba, o son cubano. Pero todo son hipóteses e non temos resposta.

É un período longo, de vinte anos, no que Herminio asistiu aos estudos universitarios dos seus fillos e á súa emancipación. Foron anos, tamén, cos seus momentos duros, coa perda de amigos como Cribeiro, Pablo Sanjosé, Uxío...; perdas que el acusaba enormemente. Anos nos que tamén foi asistindo á decadencia vital da súa nai, un dos seus grandes referentes éticos, que tamén o fería por dentro, de a pouco.

En 2006 todo parecía apuntar a que ía regresar a Cuba, nunha viaxe conmemorativa do 80 cumpreanos de Fidel. Tiña moita ilusión posta nesa viaxe, pero a enfermidade de Fidel impediuno. A pesar de que o comandante sobreviviu, aí sigue a día de hoxe, foi un golpe moral. Como se soubese que non habería outra oportunidade para el. 
E 2006, lembremos, é tamén o ano no que pretendía rematar esta labor memorialística: 0 ano en que se xubilou e pasou a ser profesor emérito. Pensamos que nunca deixou de crer que as súas memorias tiñan unha vocación pedagóxica, e só quería contarnos como fora a súa experiencia docente. $O$ que veu despois, durante a xubilación, xa era algo engadido.

\section{0 paseante}

Nestes trinta anos, camiñaba e paseaba gozoso polas rúas de Santiago, acompañado dos amigos, e asistía a canto evento cultural lle interesaba, e paseaba coa muller, máis paseniño, ou paseaba só, camiño da facultade, coas súas grandes zancadas. Baixo a choiva e o vento. Sentía predilección polo vento (temos unha foto tomada a carón dos Peites do Vento, unha obra de Chillida que o deixara abraiado; Figura 7)... Porque o que nunca fixo Herminio, nin tan sequera despois de sufrir un ataque ao corazón, en novembro de 2008, foi deixar de pasear, de percorrer rúas e camiños, meditando, falando, vivindo.

Nunha foto moi recente, de abril do ano pasado, vemos a Herminio paseando, acompañado dalgunhas persoas, falando con elas, camiñando cara unha vella casa de dous pisos, nunha pequena aldea de Galicia (Figura 8). A aldea é Meilide. A casa é a vella escola unitaria, a súa primeira lembranza. As persoas son os seus irmáns e algúns veciños de Meilide, os seus primeiros compañeiros e amigos. Aí están todos, tantos anos despois, rememorando e revivindo aqueles anos escuros e, porén, tan luminosos. É unha foto que reflicte a vida, e que adquire todo o seu poder evocador agora, hoxe.

Os paseantes sempre deixan pegada nos espazos que percorren. Herminio era un paseante; moitos dos seus espazos, como Meilide, xa foran evocados por el. De outros moitos, como Montluçon, Avignon, Aluche, Sisán, Covarrubias, Compostela... deixou testemuñas, orais ou escritas, dispersas ao longo de todo este tempo, lanzadas ao mundo, pero non unhas memorias froito dunha reflexión longa, dolorosa. Esa dor é, agora, para nós, que intentamos achegarnos con alegría ao que a súa imaxe nos suxire: Herminio, un ser que amaba os espazos nos que viviu, coas súas cousas e a súa xente.

Quero pensar que, nunha noite de inverno como esta, con frío e choiva, aínda poderemos saír a escoitar, baixo os soportais de Compostela, os seus pasos firmes nos charcos, a súa mirada agradecida, a súa voz entusiasta, a súa risa franca... 


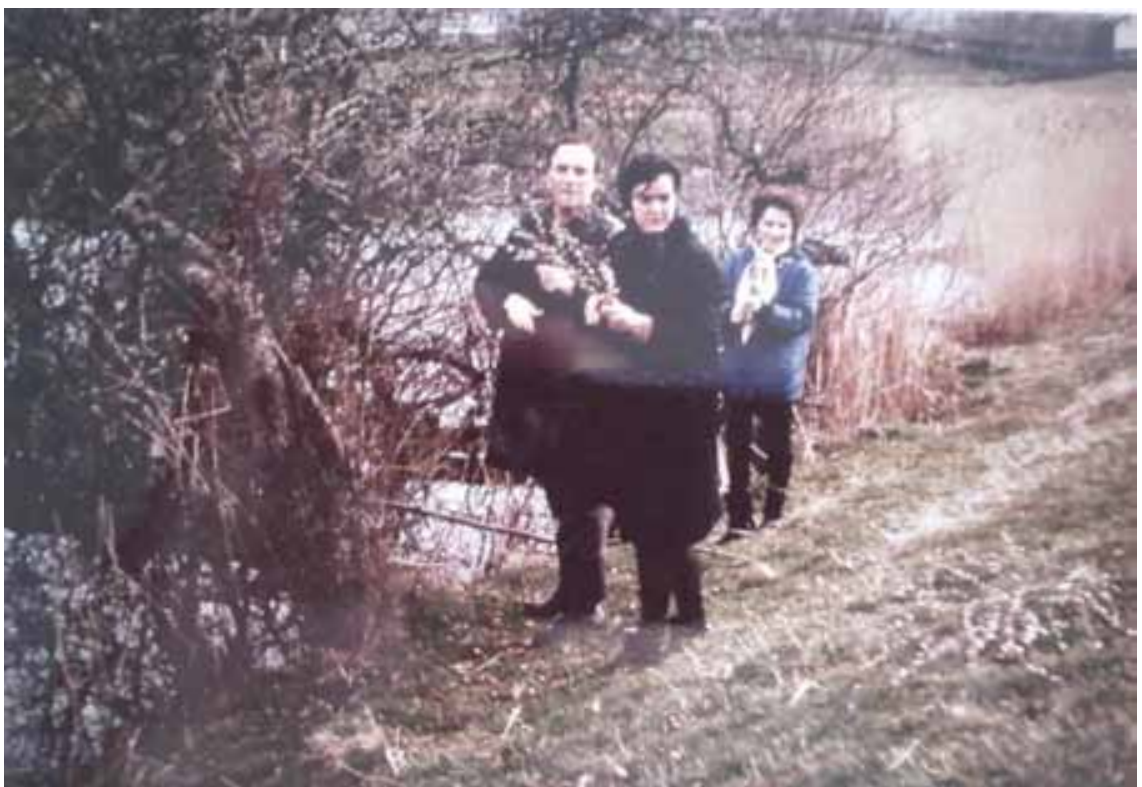

Figura 1. Collendo flores coa súa muller, Merche, e Janinne Dugne, na ribeira do Lago de Menet, preto de Montluçon (Francia), en 1966.

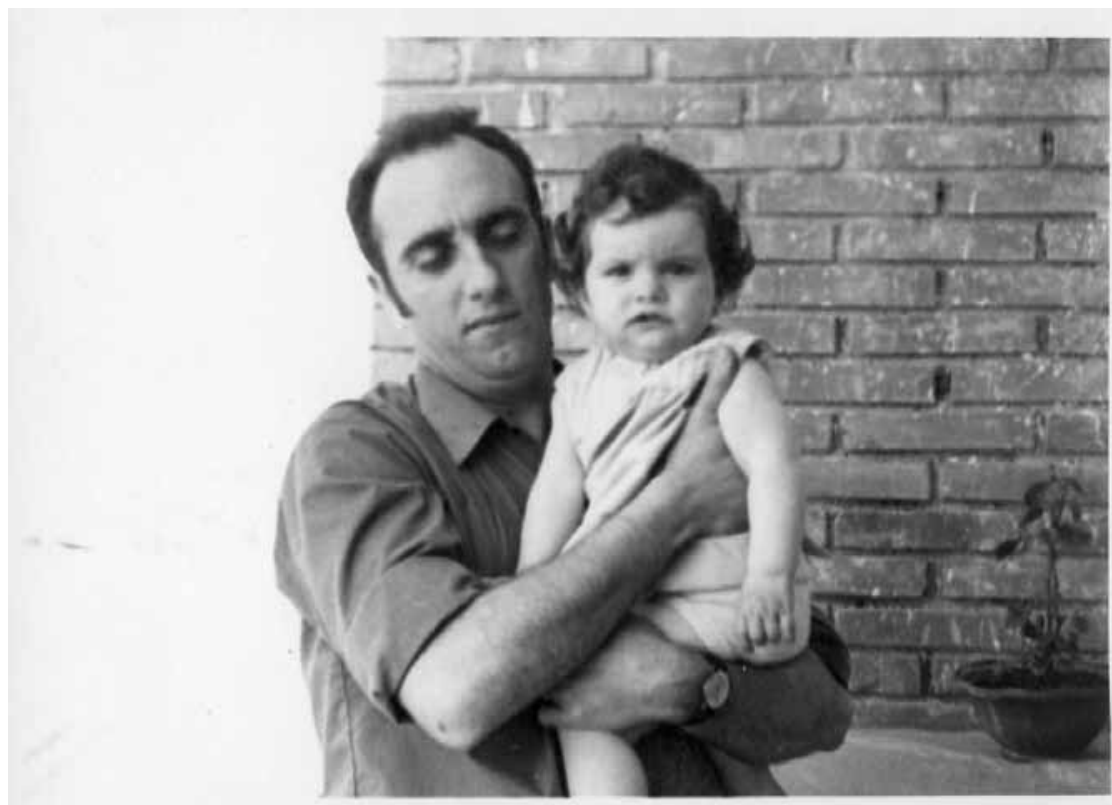

Figura 2. Coa súa primoxénita, Sonia, nun balcón de Madrid, probablemente de Aluche, en 1968. 


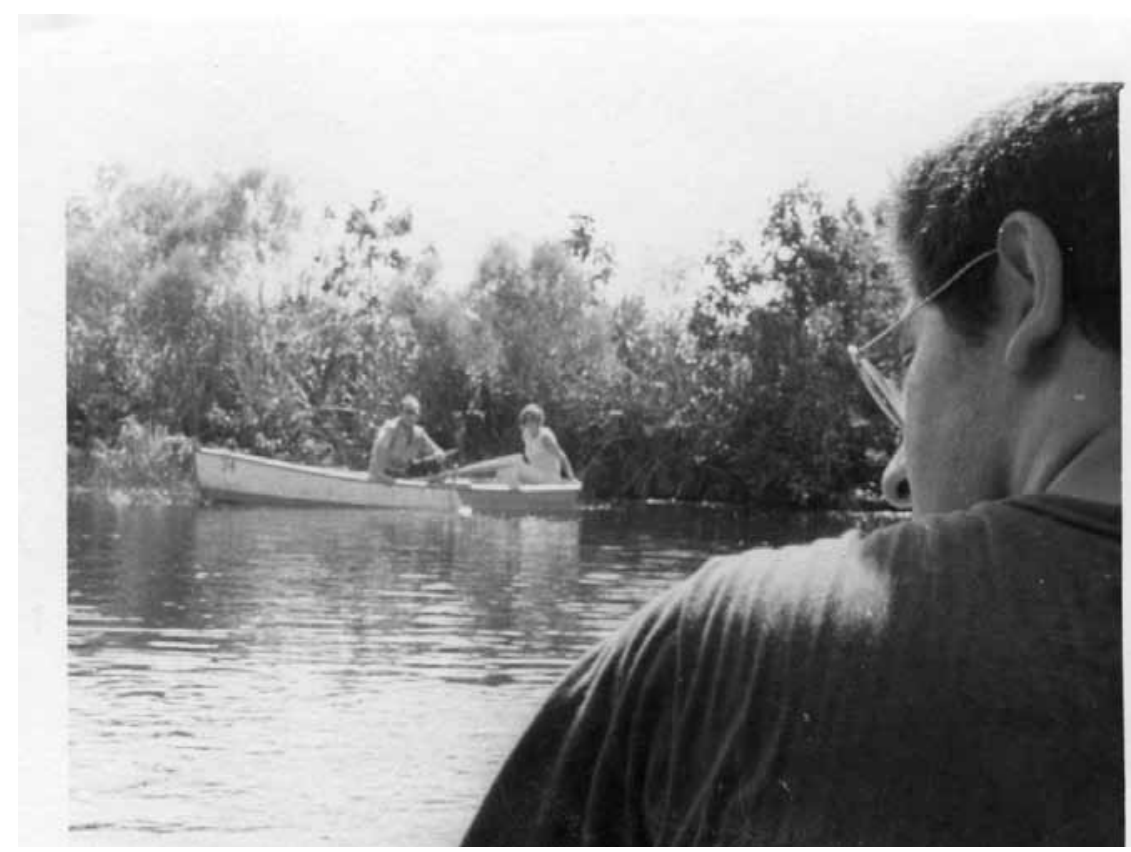

Figura 3. Nunha canoa, en Guamá (Cuba), avistando caimáns, en 1971.

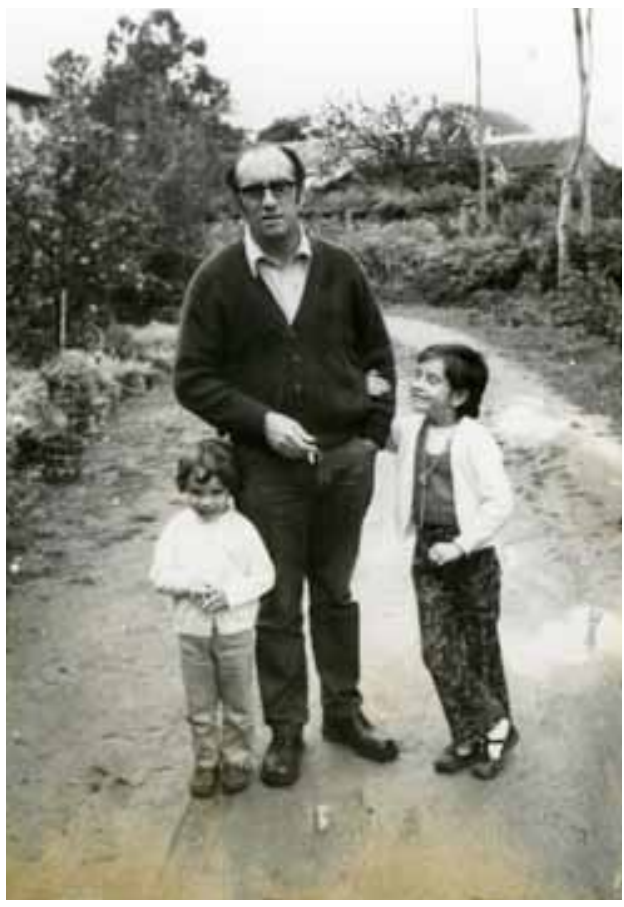

Figura 4. Cos seus dous fillos ao pouco de ter retornado a Galicia (1976), en Sisán (Ribadumia), terra do seu pai, Herminio. 


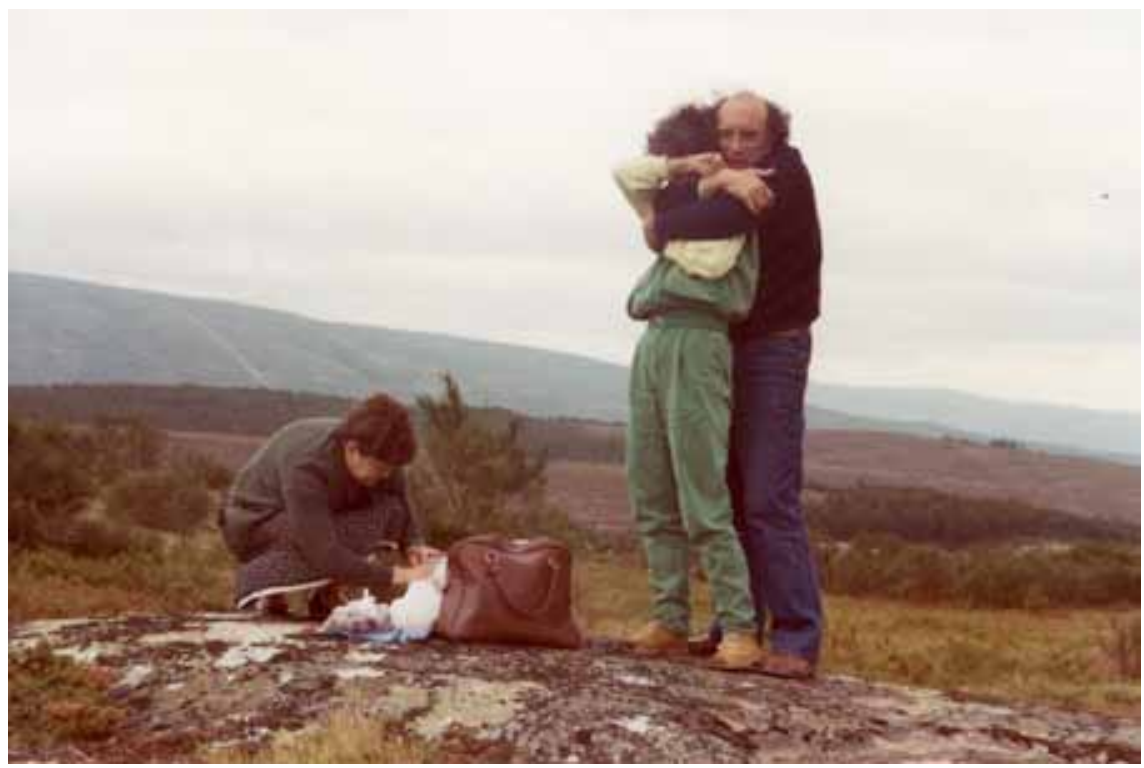

Figura 5. Preparando o xantar campestre nalgures, quizais en Zamora, cara 1983.

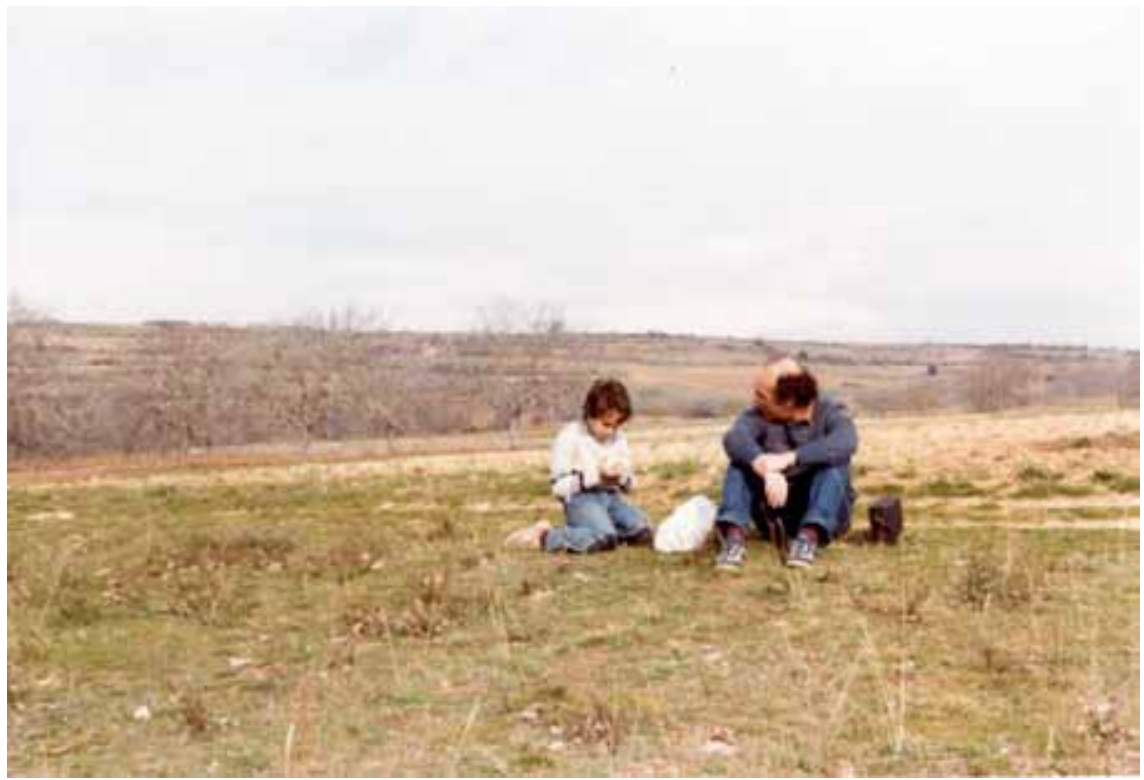

Figura 6. Recollendo fósiles co seu fillo David, en 1983, moi preto de Covarrubias (Burgos), terra da súa muller. 


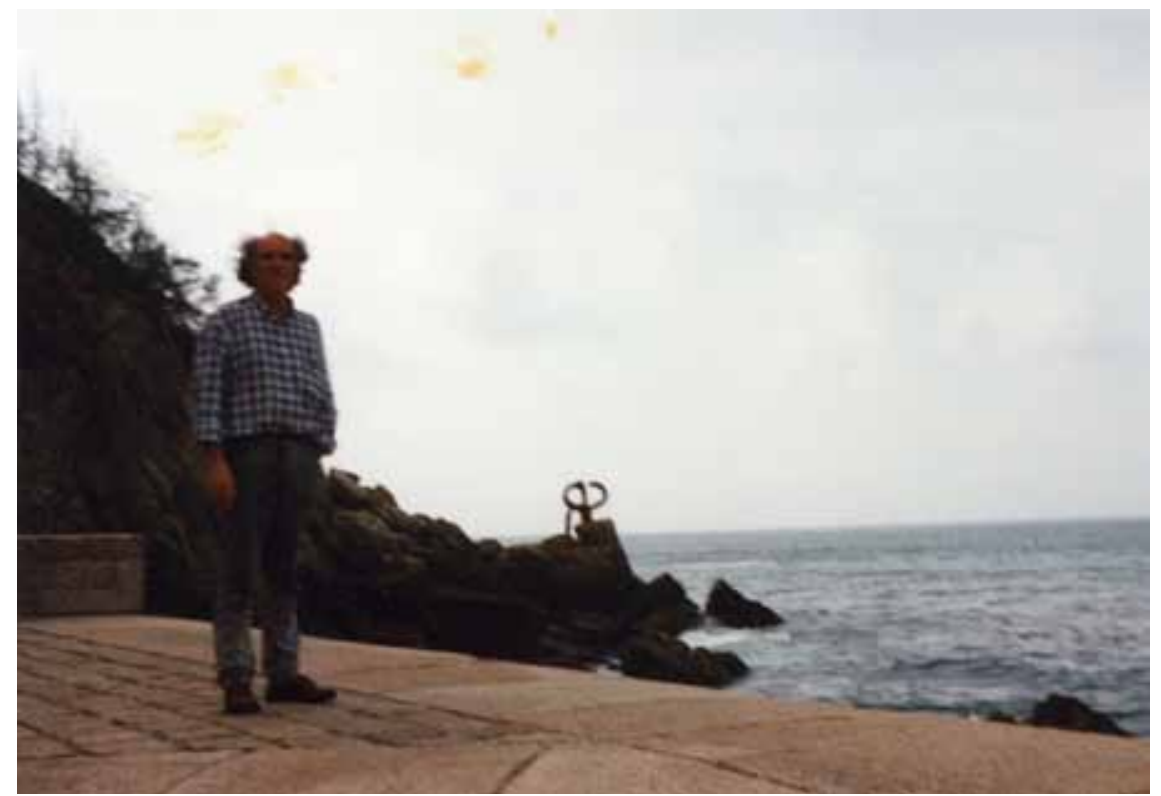

Figura 7. A carón da obra de Chillida, en Donosti, en 1990.

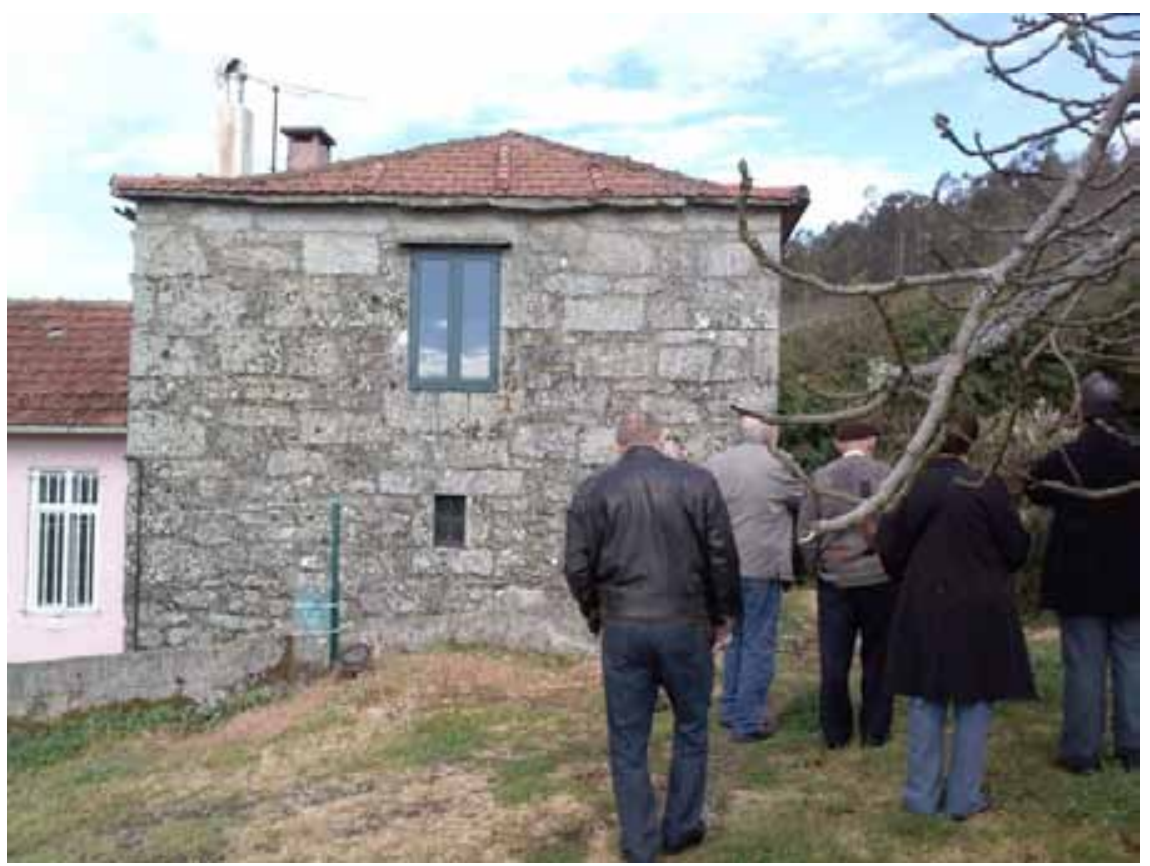

Figura 8. A súa derradeira visita á aldea da súa infancia, Meilide, moi preto de Cerdedo. A casa que se aprecia na imaxe é case o seu primeiro fogar, e tamén a escola unitaria onde ensinaba a súa nai, Concha. 